\title{
Complutum
}

ISSN: 1131-6993

\section{El guardián Modesto González y la historiografía de la arqueología mexicana ${ }^{1}$}

\author{
Sam Holley-Kline ${ }^{2}$
}

Recibido: 08 de enero de 2019 / Aceptado: 20 de mayo de 2019.

Resumen. La historiografía de la arqueología mexicana suele enfocarse en los hallazgos y las interpretaciones de los arqueólogos conocidos; tal ha sido el caso de la zona arqueológica El Tajín, Veracruz. Investigaciones recientes en la historia de arqueología han analizado los contextos sociohistóricos de la disciplina, incluso los papeles de los trabajadores. Este artículo, empleando las herramientas teóricas de Michel-Rolph Trouillot, analiza la vida y obra del guardián Modesto González (c. 1890-1971), uno de los primeros empleados federales que trabajo en la zona arqueológica El Tajín. De acuerdo con investigación archivística y etnográfica llevado a cabo en 2016-2017, se elabora una narrativa sobre la vida de González, su labor como guardián de El Tajín, sus aportaciones a la antropología mexicana y sus creencias sobre la zona arqueológica. A partir de ahí, se explora el por qué del silencio de la historiografía de El Tajín sobre Modesto González, como manera de reflexionar sobre los silencios en la historiografía de la arqueología mexicana. Se concluye con propuestas para avanzar en el análisis de los trabajadores en la historiografía de la arqueología.

Palabras clave: Historia de la ciencia; Historia de la arqueología; arqueología mexicana; El Tajín; trabajo en arqueología

\section{The guardian Modesto González and the historiography of Mexican archaeology}

\begin{abstract}
The historiography of Mexican archaeology tends to focus on the findings and interpretations of well-known archaeologists; such has been the case for the archaeological site of El Tajín, Veracruz. Recent research in the history of archaeology has analyzed the sociohistorical contexts of the discipline, including the roles of workers. In this article, I employ theoretical tools developed by Michel-Rolph Trouillot to analyze the life and work of site guard Modesto González (c. 1890-1971), one of the first federal employees to work in El Tajín. Based on archival and ethnographic research conducted between 2016-2017, I elaborate a narrative about González's life, his work as a guard at El Tajín, his contributions to Mexican anthropology, and his beliefs about the archaeological site. From there, I explore Modesto González's silence in El Tajín's historiography, as a means of reflecting on the silences present in the historiography of Mexican archaeology. I conclude with proposals to advance analyses of workers in the historiography of archaeology. Keywords: History of science; history of archaeology; Mexican archaeology; El Tajín; archaeological labor.
\end{abstract}

Sumario: 1. Introducción. 2. La historiografía de la arqueología mexicana. 3. La historia de la arqueología en El Tajín. 4. El planteamiento y los métodos. 5. La vida y obra de Modesto González. 5.1 La labor arqueológica de Modesto González. 5.2. La labor antropológica de Modesto González. 5.3. Perspectivas totonacas sobre El Tajín. 6. El silencio sobre Modesto González. 7. Conclusión. 8. Bibliografía.

Cómo citar: Holley-Kline, S. (2019): El guardián Modesto González y la historiografía de la arqueología mexicana. Complutum, 30(1): 13-28.

\footnotetext{
1 Una versión preliminar de este trabajo se presentó en el $3^{\circ}$ Congreso Internacional sobre Investigaciones del Mundo Totonaco en 2018. Se agradecen los comentarios del maestro Humberto Medina González, la arqueóloga Judith Alva Sánchez, el doctor Daniel Nahmad Molinari y la licenciada Elizeth Rivera Atzin. Los comentarios de dos dictaminadores anónimos ayudaron a precisar los argumentos aquí presentados, por lo cual también se les agradece. Se financió el trabajo de campo en México con una beca Fulbright-Hays Doctoral Dissertation Research Abroad (P022A1600-33), y la investigación archivística en el ITKEA con una beca Wenner-Gren Dissertation Fieldwork Grant (9383). Las traducciones al español son del autor. Este artículo se dedica a Maclovio Calderón Loreto y Epifania González Méndez.

2 PhD Candidate. Department of Anthropology. Stanford University s.holleykline@gmail.com
} 


\section{Introducción}

El trabajador Modesto González González (c. 1890-1971) no es autor de ninguna publicación sobre la zona en la que trabajó la mayor parte de su vida: El Tajín (Veracruz, México). Tampoco realizó informes que quedaran incluidos en el Archivo Técnico de la Coordinación Nacional de Arqueología del Instituto Nacional de Antropología e Historia (INAH). Sin embargo, analizar su vida y obra nos ofrece una aportación importante a la historiografía de la zona arqueológica El Tajín, con implicaciones para otras zonas arqueológicas en México y más allá. En este trabajo, exploro la vida y obra de Modesto González, al igual que su silencio en la historiografía de El Tajín, de acuerdo con investigaciones archivísticas e historias orales recogidas durante el trabajo de campo etnográfico en El Tajín en el período 2016-2017.

El trabajo se divide en cuatro secciones. Primero, repaso la historiografía de la arqueología en México, que suele enfocarse en los trabajos de los arqueólogos, y cito estudios de caso de otras partes del mundo para enfatizar el papel de los trabajadores en el desarrollo de la arqueología. Segundo, reseño la historia de la arqueología en El Tajín, tal como se ha escrito. Tercero, reúno y describo lo que podemos saber sobre la vida y obra de González en El Tajín, dando a conocer sus datos biográficos, su labor en esta zona arqueológica, su trabajo como informante clave con la antropóloga norteamericana Isabel Kelly y sus perspectivas sobre el lugar. Cuarto, analizo cómo se ha excluido la historia de González de la historiografía de El Tajín, de acuerdo con categorías que desarrolla el antropólogo Michel-Rolph Trouillot (2017). Concluyo con propuestas para investigaciones futuras.

\section{La historiografía de la arqueología mexicana}

La historia de la arqueología en México, tal como se ha escrito, suele estar representada por las historias de los arqueólogos, sus personalidades, sus hallazgos e interpretaciones. En estudios conocidos como los de Bernal (1980) y Matos (1998), se analizan las obras de personajes como Leopoldo Batres, Manuel Gamio y Alfonso Caso, para entender como se ha desarrollado la arqueología. A pesar de la importancia de tales personajes en la conformación de la arqueología mexicana, también es cierto que trabajaban dentro de contextos sociales, políticos, económicos e institucionales. Por ende, otras historias de la arqueología mexicana destacan cómo los gobiernos porfirianos (1876-1911) y posrevolucionarios (1920-presente) han utilizado la arqueología para generar un pasado prehispánico monumental con el fin de fortalecer la identidad nacional y mestiza (Lorenzo 1981; Gándara 1992; Vásquez León 2003).

Aunque la arqueología mexicana es un ejemplo clásico de la arqueología nacionalista (véase Trigger 1984), es cierto que el nacionalismo no es el único sector ideológico que ha influido en el desarrollo de la disciplina. Por ejemplo, en el estudio de Ruiz (2016), el género y las expediciones arqueológicas extranjeras juegan papeles fundamentales en la consolidación de la disciplina entre 1890 y 1930 (véase también Rutsch 2007). Retomando las perspectivas de historiadores y filósofos de la ciencia, Moro Abadía comenta que "el protagonismo excesivo del nacionalismo y del colonialismo ha impedido a los nuevos historiadores examinar otros procesos que han determinado la historia de la arqueología" (2012: 185; véase también Moro Abadía, 2010). Dando el siguiente paso, los editores de una edición especial de History of Science enfatizan que las fronteras epistemológicas que distinguen la arqueología como disciplina, tanto como las prácticas, instituciones y fuentes archivísticas, deben de ser temas de investigación - hasta que la categoría de "la historia de la arqueología", como tal, sea obsoleta (Carruthers y Van Damme, 2017).

Esta línea de análisis, que no asume las fronteras epistemológicas entre la ciencia y sus contextos, también se relaciona con una amplia literatura en los estudios de la ciencia que busca entender los otros actores sociales y materiales que influyen en su constitución como tal (p. ej. Latour 1987) - como prácticas burocráticas existentes (Podgorny 2015) o "los técnicos invisibles" (Shapin 1989). En el caso de la arqueología, una variedad de estudios ha tratado de hacer visible los papeles de los trabajadores: obreros, excavadores, técnicos y guardianes. Por ejemplo, en un análisis de los excavadores Aymara de Tiwanaku, Bolivia, Leighton (2016) argumenta que producen una práctica híbrida, es decir, Aymara/indígena y arqueológica/científica a la vez. El estudio de Shepherd (2003) analiza el archivo fotográfi- 
co del arqueólogo sudafricano John Goodwin para dar a conocer la labor local en el trabajo arqueológico, ya que la dinámica colonial en que operó el arqueólogo descalificó las aportaciones de los excavadores indígenas (véase también Riggs 2017). El trabajo reciente de Mickel (2019) analiza la labor arqueológica con un marco marxista para acentuar tanto la alienación como la agencia y pericia de trabajadores en la arqueología del Medio Oriente. A partir de su reseña histórica de la metodología en la arqueología europea, Berggren y Hodder (2003) argumentan que la arqueología de campo facilita el empleo de trabajadores no especializados y con sueldos bajos, lo que conlleva a consecuencias éticas y analíticas.

Para el caso mexicano, ya existen unos estudios del trabajo en la arqueología. Para el estudio de Bueno (2016), unos de los actores más importantes en la arqueología porfiriana fueron los conserjes; empleados federales que se encargaron de mantener y vigilar las zonas arqueológicas del país. El trabajo de Breglia (2005) describe el papel de los custodios de Chichén Itzá en la reproducción de aquel sitio, así como sus perspectivas sobre el lugar; en vez de enfatizar la descendencia de los antiguos mayas que construyeron la ciudad, se enfocan en sus trabajos o historias familiares de labor en la zona. Para el caso de El Tajín, Salas Landa (2018) describe cómo la práctica de la reconstrucción monumental suele ocultar los sustentos precarios de los trabajadores locales. En contraste, el estudio de Anderson (2015) resalta la cooperación entre arqueólogos y trabajadores que se ha desarrollado durante casi 70 años de investigación en Tula, Hidalgo.

En resumen, la historiografía de la arqueología mexicana suele estar centrada en personajes conocidos, o resaltar la cuestión del nacionalismo como factor determinante en la conformación de la disciplina. Estudios realizados en México y en otras partes del mundo se centran en los trabajadores, e indican que éstos juegan un papel fundamental en la interpretación y el manejo de la arqueología, el cual, por lo general, no ha sido reconocido en la historiografía. Como argumento en la si- guiente sección, la arqueología veracruzana (y, como resultado, la historia de la arqueología en El Tajín) también forma parte de esta tendencia.

\section{La historia de la arqueología en El Tajín}

La que es, sin duda, la zona arqueológica más conocida del estado de Veracruz, El Tajín, se encuentra en el municipio actual de Papantla, al norte del estado (véase Figura 1). La zona se trata de un estado y centro ceremonial que tuvo su auge durante el Epiclásico (Pascual 2009) aunque su cronología, al igual que la filiación étnica de sus pobladores, siguen siendo temas de debate (véase García Payón 1971; Wilkerson 1987; compare con Brueggemann 1993; 1991a). Se dio a conocer por una publicación anónima en la Gaceta de México el día 12 de julio de 1785 (López Luján 2008), y fue objeto de estudio para Pedro José Márquez (1972) y Alejandro von Humboldt (1811). Entre las primeras expediciones arqueológicas se encuentra la de la Comisión Científica de Cempoala de 1891-1892, a cargo de Francisco del Paso y Troncoso (Galindo y Villa 1912). Los primeros trabajos de desmonte y reconstrucción se llevaron a cabo por Agustín García Vega (1939; véase también Salas Landa 2018) entre 1934 y 1938; asimismo, los primeros estudios de la cerámica datan de esta época (Du Solier 1945). José García Payón llegó a El Tajín alrededor de 1938, y realizó varias temporadas de excavación, reconstrucción y mantenimiento hasta la década de los 1970s (Ruíz Gordillo 2002). Juergen Brueggemann (1992) y el Proyecto Tajín de 1982-1992 hicieron trabajos de excavación, restauración, catalogación e interpretación, gracias a un equipo multidisciplinario de arqueólogos, arquitectos, restauradores y antropólogos. Desde 1992, Arturo Pascual Soto (2009) ha llevado a cabo excavaciones en El Tajín y los centros cercanos, mientras Patricia Castillo (2011) investiga cuestiones del paisaje y organización urbana mediante datos LIDAR. 


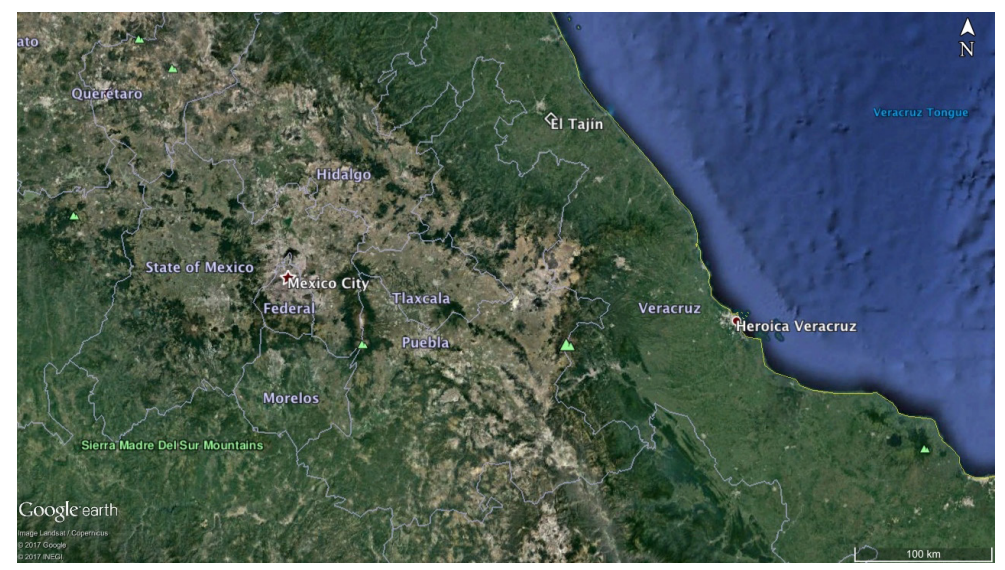

Figura 1. La ubicación de El Tajín.

Fuente: elaboración del autor a base de Google Earth.

Por lo general, así se ha escrito la historia de la arqueología en El Tajín. En estudios de síntesis (p. ej. Brueggemann 1992; Wilkerson 1987; Piña Chan y Castillo Peña 1999; Ladrón de Guevara 2010) se suelen tratar y/o mencionar estos proyectos y arqueólogos de esta manera. Hay pocos trabajos dedicados a la historia de El Tajín en sí, y los que hay son más bien sobre las cronologías de las investigaciones arqueológicas que se han llevado a cabo en la zona (sin embargo, véase Salas Landa 2018). En resumen, se puede decir que la historiografía de El Tajín está enfocada en los debates sobre la cronología y la filiación étnica; con los arqueólogos como protagonistas. Lo mismo debe ser el caso en varias zonas arqueológicas en México (con las excepciones de Teotihuacán y Chichén Itzá). En la siguiente sección, justifico el análisis de la carrera de Modesto González y planteo lo que se conoce sobre su vida y obra.

\section{El planteamiento y los métodos}

Durante el trabajo de campo para mi tesis de doctorado en antropología, pasé varias temporadas en la zona arqueológica de El Tajín, entre 2012 y 2017. Una vertiente de mi investigación trató de la historia laboral de la zona, siguiendo los estudios arriba mencionados. En varias ocasiones, custodios de la zona arqueológica y habitantes de la comunidad de El Tajín nombraron a Modesto González como el primer trabajador de esa área. Los datos etnográficos fueron escasos: nadie supo cuando entró a trabajar, ni cómo, pero muchos recordaron que trabajó hasta la vejez y su fallecimiento.
En referencias publicadas, pude encontrar comentarios sobre Pedro Pérez Bautista, quien desempeño su trabajo como encargado de la zona entre 1964 y 1992 (Nahmad Molinari 1998) pero había muy poca información sobre Modesto González.

Su carrera abarcó una época un poco más larga que la de José García Payón, y no faltan trabajos que traten de la vida de este conocido arqueólogo (p. ej. Ruiz Gordillo 1988; 2002; García Payón y Ruiz Gordillo 1993; Daneels 2006; Ávila 2007; Brizuela 2009). Asimismo, García Payón está presente en el nombre de la calzada que conduce a la zona (la Calzada Payón, como le dicen), y en varios eventos de conmemoración. El $120^{\circ}$ aniversario de su nacimiento, por ejemplo, se celebró con una exposición de sus efectos personales en el Museo de Antropología de Xalapa y un conversatorio en la Facultad de Humanidades de la Universidad Veracruzana, donde participaron varios de sus exalumnos. Por otro lado, en la zona arqueológica, se renovó una cuadra en homenaje a García Payón afuera de las oficinas, lo cual también materializa la presencia de este arqueólogo en la zona.

Modesto González, al igual que García Payón, pasó su vida laborando en El Tajín. ¿Por qué entonces es tan desconocido? Se puede creer que es por su origen campesino, el hecho de que su lengua materna era el totonaco o su falta de trabajos escritos y archivados. En contraste, García Payón, como los demás arqueólogos, dejó un legado historiográfico: trabajos publicados, ponencias y archivos.

Sin embargo, la ausencia de González es parte de un proceso historiográfico más amplio, del cual la falta de trabajos escritos es solo una 
parte. Para analizar cómo se le ha excluido de la historiografía de El Tajín, y cómo se puede reparar esto, merece la pena considerar el estudio del Michel-Rolph Trouillot (2017). Este antropólogo tiene como objetivo entender cómo el ejercicio del poder influye en el de escribir la historia. El silencio, al igual que la narración, determina cómo se escribe la historia; es decir, se relacionan dialécticamente (véase Trouillot 2017: 39). Escribir la historia es un proceso, y el silencio entra en diferentes etapas y con distintos grados, por parte de diferentes actores, de acuerdo con el ejercicio del poder: "cualquier narración histórica es un montón de silencios, el resultado de un proceso singular, y en consecuencia la tarea necesaria para deconstruir estos silencios variará" (Trouillot 2017: 23).

Como herramienta heurística, este autor describe cómo el silencio entra en la producción de la historia en cuatro momentos:

El momento de la creación del hecho (la elaboración de las fuentes); el momento del ensamblaje de los hechos (la construcción de los archivos); el momento de la recuperación del hecho (la construcción de las narraciones); y el momento de la importancia retrospectiva (la composición de la Historia en última instancia). (2017: 23)

Por el presente estudio, la historia de El Tajín, tal como la presenté en la sección anterior, está repleta de silencios, entre otros, el de Modesto González. De acuerdo con Trouillot (2017), el silencio se define en términos amplios; en este caso, se refiere a la falta de atención al trabajo que desarrolló González en El Tajín, tanto como guardián como informante de Kelly, así como a las percepciones locales del pasado prehispánico. Esta investigación, primero, consiste en reelaborar una narrativa histórica de El Tajín enfocada en González, la cual demuestra que el silencio no es el resultado de una mera falta de información. Segundo, con la evidencia sobre la vida y el trabajo de González ya proporcionada, se emplearán las herramientas teóricas de Trouillot (2017) para entender de dónde viene este silencio.

Con el fin de hacer esta narrativa, recurrí a técnicas históricas y etnográficas. En primer lugar, realicé entrevistas no estructuradas y grabadas con familiares de Modesto González, incluso su hijastro, Maclovio Calderón Loreto (dos entrevistas, por un total de casi tres horas), y una hija, Epifania González Méndez (dos entrevistas, por un total de casi cuatro horas), quienes todavía viven en la comunidad de El Tajín. Como complemento, conversé de manera informal sobre Modesto González en la comunidad durante observación-participante, y en la zona arqueológica de El Tajín. En segundo lugar, efectué una investigación archivística en varios archivos pertenecientes al INAH en la Ciudad de México. Me concentré en el Archivo de la Dirección del Departamento de Monumentos Prehispánicos (ADDMP), el Archivo Técnico de la Coordinación Nacional de Arqueología (AT-CNA) y la Colección Coordinación Nacional de Recursos Humanos del Archivo Histórico Institucional (AHIINAH, Colección CNRH), donde registré y tomé fotografías de nombramientos, informes y hojas de servicio relacionados con el trabajo en El Tajín -especialmente los que trataron de Modesto González. Además, extraje datos sobre Modesto González de otros archivos que investigué para otros temas de la tesis, incluyendo el Archivo General del Estado de Veracruz (AGEV) y los National Anthropology Archives (NAA) de los Estados Unidos. En tercer lugar, llevé a cabo otra investigación archivística en el Isabel T. Kelly Ethnographic Archive (ITKEA), en la Biblioteca DeGolyer, Southern Methodist University, Dallas, Texas. La antropóloga norteamericana Isabel Kelly (19061982) realizó trabajo de campo en El Tajín en 1947 y 1948 (véase Pérez Lizuar 2014, sobre Kelly), y empleó a González como informante clave. Por lo tanto, el diario de campo y censo de Kelly tiene muchas referencias sobre él.

\section{La vida y obra de Modesto González}

Modesto González fue tan solo un trabajador en una zona arqueológica en un país repleto de ellas. Sin embargo, poner en valor su vida y obra subraya la importancia de los trabajadores para la práctica de la arqueología y el manejo del patrimonio cultural del país. Para este fin, empleo el método histórico de la biografía (Givens 1992). Si la historiografía de la arqueología mexicana suele estar centrada en los arqueólogos conocidos, la apropiación del método biográfico con un trabajador como sujeto constituye otra manera de reposicionar los silencios de la historiografía. Es decir, esta narrativa sobre Modesto González aquí elaborada funciona como un tipo de contrapeso historiográfico, dado el énfasis en personajes como José García Payón. 
Sin embargo, sigue siendo cierto que este tipo de narrativa biográfica se puede interpretar como una teoría de historia "gran hombre", en la que la historia de El Tajín se mueve nada más por los esfuerzos de Don Modesto (véase la crítica de Lomnitz 2001: 212-227). Sin negar esta crítica, en este caso, considero que el enfoque particular del método biográfico es la mejor manera de ilustrar el detalle que dan las fuentes aquí desarrolladas y, por ende, el potencial de los materiales archivados y publicados para reconstruir otras historias de la arqueología mexicana. Con este fin, y para hacer esta biografía, empiezo con un esbozo de la matriz histórica y social en la que se desarrolló González en la comunidad de El Tajín y en las instituciones que manejaron el patrimonio cultural mexicano. Sigo estas directrices en la elaboración de su labor como trabajador, sus creencias sobre El Tajín y su labor como informante clave para Isabel Kelly.

Según sus hijos, González (véase Figura 2) nunca supo en qué fecha nació. Sus padres eran Tomás González y Nicolasa González Mata, ambos de El Tajín. Al parecer, su padre había sido militar: sobre Tomás González, un vecino le contó a Modesto que "hacían levas en la gente que iba a Papantla; [al vecino] le agarraron una vez, y a [Tomás González] también, y los llevaron a luchar por Juárez. Decía que Porfirio Díaz se había levantado contra Juárez, y que luego envenenaron a Juárez. Los llevaron a los de la leva hasta Tampico"1. Sin embargo, muy poco conoció a sus padres; fueron sus padrinos de bautizo, la familia de Ignacio de la Cruz, quienes lo criaron.

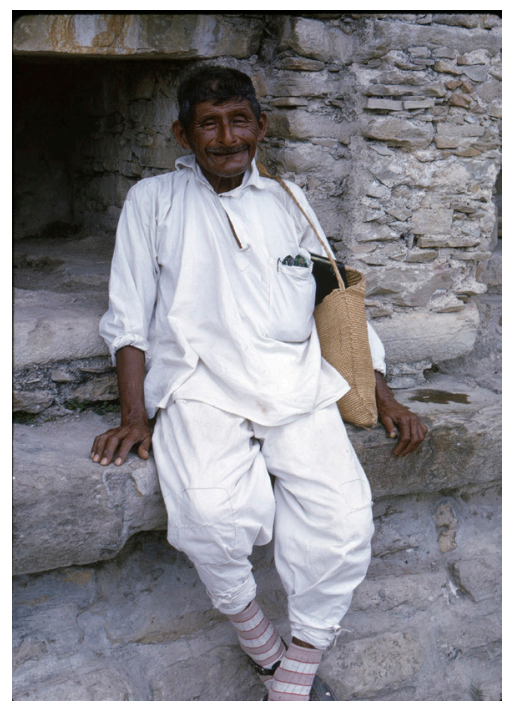

Figura 2. Modesto González en 1947

Fuente: ITKEA, serie 2, c. 18, encuadernador 1, diapositiva 055 .
De acuerdo con las edades que proporcionó a la entonces Dirección de Arqueología ${ }^{2}$, nació por 1890 en El Tajín, Veracruz. En esta época, la zona de Papantla se encontraba en el proceso de la desamortización de las tierras comunales, un proceso que Emilio Kourí describe como "un cuarto de siglo de expansión económico discordante y [con] una terrible convulsión social... los comerciantes de los pueblos y los jefes totonacos reinaban supremos, muchos agricultores indígenas eran de todo, menos independientes" (2013: 397). En 1948, Modesto González recordó este tiempo como uno durante el cual "cada uno sembraba y hacia su milpa y su casa dónde quería"3. González creció cerca de la zona arqueológica de El Tajín, que fue visitada por la Comisión Científica de Cempoala de 1891-1892 (Galindo y Villa 1912; también véase Holley-Kline 2015). Como argumenta Bueno (2016), fue durante el Porfiriato cuando se establecieron los fundamentos de la arqueología mexicana estatal, tales como el uso del pasado prehispánico para fortalecer la identidad nacional, la posesión federal de monumentos arqueológicos y el sistema de guardianes. En sus formas más elementales, estos aspectos de la arqueología porfiriana sobrevivieron la Revolución.

Por su parte, Modesto González participó en la Revolución de joven; se acordó de ella en una entrevista con Ángel Palerm:

Luego vino la Revolución contra Porfirio Díaz. Pero hasta aquí no llegaron peleando los carrancistas. Los federales agarraron como a quince o veinte de nosotros, y nos llevaron hasta más allá de Coatzintla, dicen que a recibir a los carrancistas. Se metieron por Tajín, por el Chote, y por más lugares; sólo Papantla quedó federal. Nos volvieron a agarrar, esta vez los carrancistas, para hacer rondas y guardias, hasta que los carrancistas entraron en Papantla y los federales salieron huyendo ${ }^{4}$.

Por aquellas fechas, hubiera podido entrar a trabajar en El Tajín, aunque no se sabe exactamente cuándo. De acuerdo con el censo de Ke1ly, entró como "ministro conservador, cuando entraron los Carrancistas"s. Puede ser que trabajaba de alguna forma antes de su primer nombramiento. Es común escuchar algo similar a lo que me comentó un custodio jubilado, "primero, no le pagaban [a Modesto], nomás iba a limpiar la zona, ya después le empezaron a pagar... [no se sabe porque, pero] a lo mejor 
le gustó como estaban las pirámides". Sin embargo, el primer nombramiento archivado para Modesto González es de "conserje de $5^{\text {a }}$ clase, con el sueldo diario de $\$ 1.50$ " con fecha del día 1 de junio de $1923^{6}$.

La dependencia que contrató a González en ese tiempo fue la Dirección de Antropología de la Secretaria de Agricultura y Fomento, formada en 1917. Esta dependencia, que estuvo a cargo del manejo de la arqueología en México, sufrió varios cambios institucionales antes de la fundación del INAH en 1939. Para 1926, ya era la Dirección de Arqueología de la Secretaria de Educación Público, que se había fundado en 1921. Después de la promulgación de un nuevo Ley de Monumentos en 1930, se creó el Departamento de Monumentos Artísticos, Arqueológicos e Históricos, cuya Dirección de Arqueología se volvería el Departamento de Monumentos Prehispánicos del INAH después de la creación de esta última en 1939 (véase Martínez Acuña 2010: 24-25; Olivé 1995: 29-30). Con estos cambios institucionales, el nombramiento de González también cambió. Por ejemplo, su puesto era guardián conservador en 1925, vigilante por 1930 y guardián por $1931^{7}$. Sin embargo, las prácticas del trabajo, las cuales describo a continuación, seguían siendo las mismas.

En esa época, se trabajó con pico, pala, machete y coa en la zona arqueológica. Al parecer, con el pasar del tiempo y los años, Modesto González empezó a desarrollar trabajos menos pesados. Aún en 1959, García Payón quiso que se jubilara, por sus "condiciones físicas [que] son tales que me temo que fallezca antes de que lo jubilen, dejando a varios niños de menor edad"8. Sin embargo, siguió trabajando. Cuando se habla de él en la comunidad de El Tajín, los que lo recuerdan comentan que se iba a la zona cargando una sillita en la que se sentaba mientras arrancaba hierbas en la Pirámide de los Nichos. También se acuerdan de él como taquillero; cuando los visitantes a la zona entraban, él les pedía que firmaran un libro de registro, lo cual se aprecia en su bolsa en la Figura 2.

A lo largo del siglo XX, mientras la arqueología mexicana gubernamental se consolidó como la arqueología oficial mexicana (Gándara 1992) o la escuela mexicana de arqueología (Vásquez León 2003), orientada a la historia cultural mesoamericana, la comunidad de El Tajín se transformó. Una comunidad de agricultores y terratenientes totonacos, quienes participaron en el mercado internacional a través del cultivo de la vainilla (Kelly y Palerm 1952), fueron perdiendo sus terrenos por compraventa y despojo ganadero hasta que, comentó Kelly, "Los viejos tiempos, cuando todos los hombres eran agricultores de maíz, ya se pasaron... en vez de ser agricultores buenos, con ganancias apreciables de sus productos, se están convirtiendo en miembros desfavorecidos de la cultura "nacional"' . (véase también Velázquez Hernández 1995). En este contexto, el tener un trabajo estable como el de guardián de la zona arqueológica era una ventaja para González y su familia, ya que la agricultura tradicional se estaba volviendo cada vez menos factible.

Ya para este tiempo, Modesto González trabajaba como persona de la tercera edad, y se comenta que no se jubiló nunca; comenta su hija que dejó de trabajar aproximadamente un año y medio antes de fallecer. Un día de 1969 , estuvo caminando por el barrio del Palmar (a medio kilómetro de la zona arqueológica) cuando vio una piedra; la pateó para que no se le tropezara luego, pero se cayó y se lastimó una pierna. Le pegó la gangrena y se quedó encamado como año y medio, hasta que falleció el día 10 de enero de 1971, a la edad de más o menos 80 años, y le dieron de baja por defunción el día 17 de diciembre de $1971^{10}$; al parecer, es cierto que nunca lo jubilaron de manera formal. Durante estas fechas, los guardianes eran Pedro Pérez Bautista, Fidencio Morales, Manuel Quirino y Lázaro Hernández. Según parece, la plaza de Modesto González se congeló y no se heredó (véase, por contraste, los custodios que describe Breglia 2005).

A González le enterraron en el cementerio conocido como el míxon, en San Lorenzo Tajín. Por lo general, entre las comunidades totonacas de Papantla se suele hacer una serie de rezos y comidas rituales a los cuatro, nueve y ochenta días después del fallecimiento, y luego al cabo del año. A pesar de haber sido rezandero antes de entrar a la zona, comenta su hija que, por su contacto con personas extranjeras, González había dejado de creer en las tradiciones que se hacen alrededor de la muerte: los cuatro días, el novenario, los ochenta días y al cabo del año; no quiso que hicieran tales rituales para él. Este hecho también les llamó la atención a Ángel Palerm y Cristina Álvarez, quienes comentaron que "el escepticismo de Modesto se extiende a todos los campos de lo sobrenatural, incluyendo la religión y la supervivencia del alma""1. 
De todos modos, después de su fallecimiento, su hija temía que no estaba descansando: "desde que él falleció, yo soñaba con él, todas las noches soñaba que él estaba parado allí; que no estaba muerto... le hicimos los nueve días, los ochenta días, y justo desde que le hicimos los ochenta días fue que ya no soñé con él. Él lo quería, creo... hasta la fecha no lo he soñado más". A lo largo de su vida, se juntó con María Antonia Méndez de Tajín, luego María Loreto de la comunidad de Talaxca y después Emilia López de la localidad de Pozo 52; tendría por lo menos diez hijos y tres hijastros, de los cuales dos, Teódulo y Rosalino González Méndez, trabajaron como guardianes en la zona arqueológica entre 1944 y 1964 . Hoy en día, tiene hijos y nietos quienes todavía viven por El Tajín y en la ciudad de Papantla.

\subsection{La labor arqueológica de Modesto González}

Cuando González se nombró conserje en 1923, ya había estado de conserje Honorato Méndez; habían existido conserjes en El Tajín desde 1902 (véase Tabla 1). Como señala Bueno (2016), los conserjes hicieron trabajo de mantenimiento, vigilancia, y apoyo a visitantes y arqueólogos. Por ende, jugaron un papel importante en representar el estado mexicano en los sitios arqueológicos.

Tabla 1. Conserjes de El Tajín, 1902-1940.

\begin{tabular}{|l|l|l|l|}
\hline Nombre & Entrada & Salida & Duración \\
\hline Leopoldo Armengual & 1 de julio de 1902 & 10 de mayo de 1906 & 3 años, 10 meses \\
\hline $\begin{array}{l}\text { Agapito Guillermo } \\
\text { Fontecilla }\end{array}$ & 10 de mayo de 1906 & 21 de diciembre de 1913 & 7 años, 7 meses \\
\hline Pedro Bautista & 1 de abril de 1914 & c. 1917 (último informe) & $\begin{array}{l}2 \text { años, } 7 \text { meses (por lo } \\
\text { menos) }\end{array}$ \\
\hline Honorato Méndez & 31 de marzo de 1921 & 11 de octubre de 1929 & 8 años, 6 meses \\
\hline $\begin{array}{l}\text { Modesto González } \\
\text { González }\end{array}$ & 1 de junio de 1923 & 10 de enero de 1971 & 47 años, 6 meses \\
\hline Manuel Pérez & 8 de octubre de 1929 & 5 de diciembre de 1930 & 1 año, 1 mes \\
\hline Erasmo Rodríguez Jaac & 1 de enero de 1931 & 1 de octubre de 1939 & 8 años, 9 meses \\
\hline Rafael Cruz Ventura & 1 de febrero de 1940 & 1 de septiembre de 1940 & 7 meses \\
\hline
\end{tabular}

Fuente: elaboración propia en base de la documentación de los expedientes correspondientes del ADDMP y AHI-INAH, Colección CNRH.

Al parecer, hubo una división del trabajo entre González y Méndez que se mantuvo después del fallecimiento de Méndez y durante el período de Erasmo Rodríguez Jaac. Aunque sus nombramientos eran iguales, a González se le suele describir como "peón". Méndez y Rodríguez rindieron informes regulares por oficio a la dependencia correspondiente que se trataban sobre la estadística de visitantes, el estado de conservación de los monumentos y las labores realizadas durante el período; además gestionaron los pagos e hicieron los trámites necesarios, por ejemplo, para préstamos ${ }^{12}$. Vivieron en la ciudad de $\mathrm{Pa}$ pantla, aproximadamente a 10 kilómetros o por lo menos a una hora de distancia a caballo por camino real.
González, al parecer, se encargó del trabajo de desmontar, chapear, arrancar hierbas y cortar brechas o senderos, y vivió en la congregación de El Tajín, cuyo fundo legal se encuentra a un kilómetro de la zona arqueológica. Aparentemente, las relaciones entre el peón y el conserje tampoco estaban muy claras entre los mismos actores. En un ejemplo, un tal Eugenio Salazar, "peón de las ruinas del Tajín ${ }^{13}$ de Papantla" que trabajaba con el entonces fallecido conserje Pedro Bautista, reportó que Honorato Méndez le "manifestó que debía hacer el trabajo solo y sin ninguna ayuda y que de no convenirme se lo manifestara para solicitar mi cese"; en la misma carta, pide a la Dirección de Antropología saber sobre sus obligaciones y propone a un tal Gregorio Bautista como conserje, 
ya que éste era vecino de Tajín. En 1907, el mismo Gregorio Bautista, le había escrito a la Secretaria de Instrucción Pública y Bellas Artes para quejarse sobre el estado de limpieza de la pirámide y proponerse como conserje. Bien puede ser que la petición de Salazar hubiese sido otro intento para dar el cargo a Bautista. La respuesta a su petición fue que "no cabe dentro de sus funciones [de peón] el hacer indicaciones para nombramiento de conserje" ${ }^{14}$.
Dada la diferencia entre conserje y peón, el hecho de que Modesto González fuera conserje por nombramiento no nos permite asumir cuáles eran sus responsabilidades en el trabajo. Sobre este asunto, un informe quincenal de José García Payón que abarca desde el 1 al 15 de septiembre de 1947 nos da una idea más detallada del tipo de trabajo que realizó González. El mismo se presenta a continuación:

\begin{tabular}{|c|c|c|}
\hline & & $\begin{array}{l}\text { Tabla 2. Los trabajos realizados por Modesto González } \\
\text { la quincena de } 1 \text { a } 15 \text { de septiembre de } 1947 \text {. }\end{array}$ \\
\hline \multirow{16}{*}{ 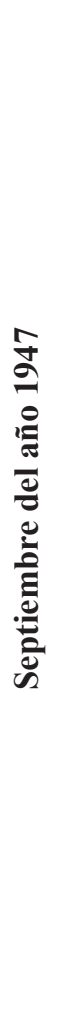 } & Día & Trabajo realizado por Modesto González \\
\hline & Lunes $1^{\circ}$ & Destroncamiento y desenraizamiento en el edificio 5 , partes sin explorar \\
\hline & Martes $2^{\circ}$ & Destroncamiento y desenraizamiento en el edificio 5 , partes sin explorar \\
\hline & Miércoles $3^{\circ}$ & $\begin{array}{l}\text { Conclusión del desyerbe de los edificios } 2 \text { y } 5 \text {, partes exploradas (empezó el } 28 \\
\text { de agosto) }\end{array}$ \\
\hline & Jueves $4^{\circ}$ & Inicio del desyerbe del edificio 1, la Pirámide de los Nichos, lado sur \\
\hline & Viernes $5^{\circ}$ & Continuación del desyerbe del edificio 1, la Pirámide de los Nichos, lado sur \\
\hline & Sábado $6^{\circ}$ & Chapeo de la entrada a la zona, de yerbas de unos 50 centímetros de altura \\
\hline & Domingo $7^{\circ}$ & Ninguna entrada; probablemente descansaron \\
\hline & Lunes $8^{\circ}$ & Continuación del desyerbe del edificio 1, la Pirámide de los Nichos, lado sur \\
\hline & Martes $9^{\circ}$ & Continuación del desyerbe del edificio 1, la Pirámide de los Nichos, lado sur \\
\hline & Miércoles $10^{\circ}$ & $\begin{array}{l}\text { Todos los guardianes participan en el destroncamiento y desenraizamiento en el } \\
\text { patio poniente del Juego de Pelota Sur y el edificio } 7\end{array}$ \\
\hline & Jueves $11^{\circ}$ & $\begin{array}{l}\text { Todos los guardianes participan en el destroncamiento y desenraizamiento en el } \\
\text { patio poniente del Juego de Pelota Sur y el edificio } 7\end{array}$ \\
\hline & Viernes $12^{\circ}$ & $\begin{array}{l}\text { Todos los guardianes participan en el destroncamiento y desenraizamiento en el } \\
\text { patio poniente del Juego de Pelota Sur y el edificio } 7\end{array}$ \\
\hline & Sábado $13^{\circ}$ & $\begin{array}{l}\text { Se termina el destroncamiento y desenraizamiento en el patio poniente del Juego } \\
\text { de Pelota Sur, y siguen con lo mismo en el edificio } 7\end{array}$ \\
\hline & Domingo $14^{\circ}$ & Ninguna entrada; probablemente descansaron \\
\hline & Lunes $15^{\circ}$ & No se trabajó \\
\hline
\end{tabular}

Fuente: elaboración propia en base del AT-CNA, Volumen 29-177. Informe de la zona arqueológica de El Tajín, Ver. (1935-1971).

El rápido crecimiento de la vegetación en la zona era, y sigue siendo, una fuerte problemática para el mantenimiento del área. La selva mediana subperennifolia es densa y crece rápidamente; los acahuales "son comunidades que tienen un dosel arbóreo cerrado que alcanza los 10-12 metros de altura... [con] un estrato arbustivo (de 2 a 4 metros) y herbáceo que cubre casi toda la superficie" (Secretaria de Desarrollo Regional 2001: 17). García Payón describió que tardó 17 días para el edificio
A, 48 días para el edificio $\mathrm{C}$ y 18 días para la fachada del edificio 1 , por estar cubiertos por cacahuapaxtle (Hamelia patens Jacq.). El trabajo también tuvo sus peligros en ese tiempo. Por ejemplo, en 1947, García Payón escribió sobre "un pequeño incidente, batallando con las nauyacas [Bothrops asper], con las que nos enfrentamos al hacer el desmonte de la zona y que matamos un promedio de cuatro al día"15. La amenaza de encontrarse con una serpiente tan venenosa como la nauyaca alude a los 
peligros de trabajar en el chapeo en la zona arqueológica.

En otras ocasiones, González fue comisionado para hacer otro tipo de trabajos. Por ejemplo, la calle Nacional de la congregación de El Tajín, que conecta la congregación con la Carretera Federal 180 y la zona arqueológica, no siempre fue la entrada principal. El camino real para llegar a Papantla sin desviarse hacia la zona arqueológica pasaba por la calle $16 \mathrm{de}$ septiembre. En 1929, el inspector honorario Ramón Castañeda mandó a González a hacer una brecha de tres metros de ancho "en vista de que había tanto monte en el camino que se dificultaba transitar por ahí a caballo"16. Es esta brecha la que luego formaría las entradas modernas a la comunidad y la zona arqueológica de El Tajín. El trabajo de desmonte, chapeo y limpieza, además de hacer esta brecha, son aquellas labores que hicieron posible la arqueología de García Payón y otros.

\subsection{La labor antropológica de Modesto González}

Algo de esta información la sabemos por otro importante trabajo que desarrolló Modesto González; en los términos de la época, fue el "informante clave" para la antropóloga norteamericana Isabel Kelly. En una carta a George Foster, Kelly explica que un hijo de Modesto (presuntamente fue Rosalino) le había guiado por la zona en 1946, y Kelly apreció su conocimiento y aptitud. Kelly pidió una carta de introducción de Ignacio Marquina del Departamento de Monumentos Prehispánicos para que los guardianes de Tajín colaborasen con ella en su estudio ${ }^{17}$. En el inicio, fue el mismo Rosalino quien iba a ser el informante clave, pagado por Kelly y su equipo de estudiantes. Por razones que Kelly no mencionó, se cambió por Modesto como "factótum general, guía, traductor e informante"; comentó Kelly que "el viejo caballero está tan encantado que pasa con nosotros como 15 horas al día, y habla de tal manera que estoy por llenar mi segundo cuaderno"18. En un trabajo posterior, Roberto Williams García describe a Modesto como "octogenario admirable, enjuto, lleno de fortaleza y ánimos... [desempeñó el trabajo] con modestia y eficiencia" (1989: 30).

En el trabajo publicado se cita a González por su conocimiento de varios temas: la historia del reparto de los terrenos, la vegetación típica del monte alto, los costos de sembrar una milpa, las creencias alrededor de los animales, los tipos de maíz - entre otros (I. Kelly y Palerm 1952). En el diario de campo de Kelly ${ }^{19}$, compuesto por aproximadamente 9.000 hojas de 5x8", y organizado por el Outline of Cultural Materials (Murdock, Clellan y Hudson 1945), se cita la fuente del contenido; se anota que González, además, aportó mucha información sobre el parentesco, las relaciones familiares y la propiedad de las parcelas. María Loreto, con quién González vivió cuando Kelly estuvo en El Tajín, también aportó varios datos sobre las relaciones entre hombres y mujeres, la crianza de los niños y los preparativos para las comidas. Mientras trabajaba para Kelly, González no trabajó en la zona arqueológica, con permiso del INAH. Después de terminar sus temporadas de trabajo de campo con Ke1ly en 1947-1948, Modesto González regresó al trabajo. Este extremo nos conduce a otra línea de investigación planteada en el siguiente punto.

\subsection{Perspectivas totonacas sobre EI Tajín}

Las perspectivas de personas que no son arqueólogos sobre su patrimonio cultural, ha sido muy desarrollada en los últimos 20 años en varias ramas de la teoría arqueológica. En esta literatura, el discurso científico de la arqueología suele descalificar perspectivas subalternas sobre el pasado (véase Nicholas y Hollowell 2007; Navarrete 2009; Gnecco y Hernández 2008; Breglia 2006, entre otros). En otras palabras, González, al igual que sus familiares y vecinos en El Tajín, deben haber tenido sus propias interpretaciones de la zona arqueológica El Tajín, que no necesariamente tenían que ver con las interpretaciones que hicieron los arqueólogos. Vale conocer estas interpretaciones para tener una perspectiva más amplia sobre la labor de Modesto González y el contexto cultural en que se desarrolló. Kelly y su equipo recogieron varias creencias durante 1947 y 1948, y en una ficha González explicó cómo se había construido El Tajín, según él:

Dicen que venía gente del norte. Estas gentes eran las que hicieron las pirámides... cuando hacían las pirámides, estaba oscuro: no había sol. Habían diablos. La pirámide no era de piedras sino de madera. Cuando amaneció -es decir, cuando salió el sol- toda la pirámide y los ídolos [figuras arqueológicas] se volvieron piedras. Querían los ídolos esconderse porque no 
conocían el sol y no sabían qué cosa era; pero no pudieron porque ya eran de piedra. El ídolo que se escondió primero se quedó escondido; no pudo salir. La gente de aquellos tiempos eran como nosotros; ya tenían metates, y de vez en cuando los encontramos enterrados. El sol salió porque Dios lo puso $^{20}$.

Para González, entonces, El Tajín se había hecho por gente como nosotros, ya que tenían metates; originarios del norte, quienes hicieron sus estructuras de madera $\mathrm{y}$, aparentemente, ídolos vivos y animados. Así como para muchas personas de la zona, él parece haber tenido una explicación para su origen relacionada con la cosmovisión local, en vez de las interpretaciones que publicaron los arqueólogos de la época.

Este tipo de creencias, sobre la naturaleza y el poder de El Tajín, también se asociaron con varias prácticas culturales; quizás la más anotada por Kelly fue el baño de los ídolos. En un borrador de un capítulo sin publicar, Kelly comenta que varias casas tenían esculturas arqueológicas debajo de sus altares familiares, y que las bañaban para pedir la lluvia en tiempos de escasez y sequía. Hasta la fecha, es común tener material prehispánico en las casas de la región. Los dos monolitos cerca de la Pirámide de los Nichos (por fotos, se sabe que son el Dios Tajín y la representación de un gobernante mencionado por Pascual Soto 2009: 66) también se trataban de esa manera: traían agua en garrafones, latas u ollas de barro, y con un guaje se sacaba agua para verter sobre las esculturas. En caso de que no llegara la lluvia luego, se podía pedir a un rezandero hacer el ritual ${ }^{21}$. Otras prácticas de ofrendas también se enfocaban en las esculturas de la zona; a Ángel Palerm le explicó González que se echaban centavos para pedir más dinero, se quemaban velas para vivir bien y no enfermarse, y se ofrecían cigarros o puros para tener suerte en la caza. Para los que vivían por El Tajín en este tiempo, la zona arqueológica no fue tanto un recurso para investigar sobre el pasado prehispánico sino un lugar poderoso para influir en el presente y futuro.

\section{El silencio sobre Modesto González}

En un inicio, me pregunté si Modesto González no formó parte de la historiografía de El Tajín porque no dejó ninguna fuente escrita, al menos, ninguna que yo haya podido localizar. Sin embargo, pensando en las categorías de Trouillot (2017) la explicación es más compleja. En la elaboración de las fuentes, es cierto que González no dejó informes como los que dejaron Agustín García Vega o José García Payón (véase García Moll 1982), por ejemplo. No obstante, se registraron varios hechos sobre su vida y obra en El Tajín en los informes rendidos al Departamento de Monumentos Prehispánicos, su documentación en la Coordinación Nacional de Recursos Humanos del INAH y, sobre todo, en el diario de campo y censo de Isabel Kelly y su equipo.

En el ensamblaje de los hechos vemos como empieza a entrar el silencio. En México, la mayor parte de los datos sobre la vida y obra de Modesto González se quedaron en el Archivo Administrativo del Departamento de Monumentos Prehispánicos y el Archivo de Concentración de la Coordinación Nacional de Recursos Humanos; poco quedó en el Archivo Técnico de la Coordinación Nacional de Arqueología. En este sentido, al arqueólogo o historiador que le interese la historia de las investigaciones arqueológicas en El Tajín generalmente se dirige a este último, al AT-CNA - aunque es cierto que la falta de publicación de este tipo de informes también constituye un problema para la disciplina (Vásquez León 2003). Es decir, en el momento de ensamblar los hechos, los informes técnicos se quedan en un solo lugar, mientras que los datos acerca del personal y la administración de la arqueología se encuentran en varios. En otras palabras, para escribir una historia de acuerdo con los arqueólogos, hay que consultar las fuentes publicadas y quizás el AT-CNA; pero para escribir una narración histórica que empieza desde un trabajador, hay que moverse entre varios archivos - y hacer los trámites correspondientes. Entre la organización de los archivos y los espacios que se ocupan, entra el silencio; no se ha dado la misma importancia a los archivos administrativos que la que se ha dado a los archivos técnicos. Por ejemplo, ya desde 1982 se cuenta con un índice para el Archivo Técnico de la Dirección de Monumentos Prehispánicos (véase García Moll, 1982); sin embargo, no hay nada parecido para ningún archivo administrativo que conozco (exceptuando el trabajo reciente de Martínez Acuña 2010).

En la manera de recuperar los hechos y hacer las narrativas también entra el silencio. Para la arqueología europea, Hodder (1989) anotó so- 
bre una tendencia de escribir informes en una forma abstracta e impersonal, sin dialogo. El mismo suele ser el caso para los informantes claves en la investigación etnográfica (Turner 2010). Estas formas de escribir los resultados de las investigaciones en la antropología y la arqueología, que también me parece apta para describir a los informes de García Payón de la época, funciona para dar a conocer datos arqueológicos importantes - pero también para silenciar la burocracia de manejo y gestión de la cual trabajadores como Modesto González forman una parte importante. De la misma forma, la práctica de la arqueología tradicional, que favorece un punto de vista científica y objetiva, suele descalificar las perspectivas de sujetos subalternos (Nicholas y Hollowell 2007; véase Navarrete 2009 para el caso mexicano).

Aun cuando los hechos acerca de la vida y labores de trabajadores fueron registrados y archivados de forma más o menos accesible, como es el caso de Modesto González, no han formado parte de ninguna narración histórica. El silencio entra porque los protagonistas de la historia de la arqueología en El Tajín son los que dejaron informes, los arqueólogos; la existencia de otras fuentes no necesariamente implica que vayan a formar parte de alguna narración histórica. Por lo mismo, a esta historia no se le ha dado la importancia retrospectiva; de alguna forma, tal ha sido el objetivo de esta narrativa biográfica.

En este caso, emplear las categorías de Trouillot (2017) ayuda a entender la complejidad del silencio de Modesto González. La falta de atención a este personaje, $\mathrm{y}$, por ende, la falta de atención a los trabajadores en la historia de la arqueología mexicana, no se debe a una mera falta de fuentes, ni a una falta de atención académica. Para entender este silencio, hay que considerar tanto la elaboración de las fuentes primarias, como la organización de los archivos, la epistemología y la manera de escribir en la arqueología, junto a la valorización del trabajo manual como tema de estudio dentro de la disciplina. La consideración de estos temas es lo que permite que se reposicionen estos silencios para ser capaz de desarrollar el tipo de narrativa que se hace en este trabajo.

\section{Conclusión}

Hoy en día, se recuerda a Modesto González como me comentó el custodio jubilado Oné- simo Juárez González, como "un señor con su traje típico de la región [calzón de manta], no como nosotros, era de blanco ${ }^{22}$, hablaba bien el totonaco". Se recuerda por haber sido de los primeros trabajadores de la zona arqueológica El Tajín, y por haber trabajado allá tanto tiempo -casi 46 años. Además de que hizo su labor incluso antes de la llegada de Agustín García Vega o José García Payón, fue el único trabajador que vivió tan cerca de la zona.

De la misma forma en que queda grabado en la memoria histórica de la zona, Modesto González suele aparecer en lugares inesperados. En 1994, la escritora Elena Poniatowska recordó de una visita a El Tajín en 1954:

Modesto González, un campesino, pastoreaba a ciento ochenta pirámides. Ciento ochenta moles bajo tierra, él era el custodio de toda esa grandeza arruinada que recorría y acariciaba todos los días como un recuerdo personal. Aún tengo presente su rostro perfilado y agudo donde los pómulos, la nariz y el mentón parecían otras tantas pequeñas y modestas pirámides (1994: 173).

Así, Modesto González quedó plasmado en las memorias de muchos que visitaron El Tajín en aquella época. En una guía para visitar México, la escritora de viajes Kate Simon recomendó al visitante de El Tajín: "busca a Modesto, el viejo vigilante que no puede estar muerto aún; su tiempo para ser llamado pasó hace tiempo, y ya se ha vuelto inmortal" (1963: 319). De alguna forma, esa inmortalidad se aprecia en el camino de la congregación de El Tajín a la Carretera Federal 180, que ya es la entrada principal a la zona, y quizás, en la estrecha relación laboral entre dicha congregación y la zona arqueológica.

En su estudio del papel de coronel Sans Souci en la revolución haitiana, Trouillot comenta que su análisis "requería un trabajo adicional no tanto en la producción de nuevos hechos sino en su transformación en una nueva narración" (2017: 48). Con este tipo de narración sobre un trabajador de una zona arqueológica espero contribuir a los objetivos historiográficos que plantean Moro Abadía (2010) con Carruthers y Van Damme (2017) sobre la historia de la arqueología. En este sentido, se une a un conjunto pequeño pero creciente de estudios sobre el papel de los trabajadores manuales en la arqueología. 
En un inicio, pareció que iba a ser difícil recuperar algo de la vida y obra de Modesto González: "las narraciones históricas se basan en comprensiones previas, las cuales se basan asimismo en la distribución del poder del archivo" (Trouillot 2017: 45). La tendencia historiográfica en la arqueología mexicana es citar fuentes publicadas y archivos técnicos para los datos e interpretaciones arqueológicas que contienen. Sin embargo, no es el arqueólogo ni la interpretación en sí lo que únicamente hace la arqueología. La historia de Modesto González cuenta con la suerte de tener una fuente archivística como la de Isabel Kelly, pero los archivos administrativos e institucionales citados aquí tratan de trabajadores de zonas arqueológicas de todo el país y de varias épocas (véase, por ejemplo, Martínez Acuña 2010). El método y las fuentes descritas aquí, entonces, resultan válidas para zonas arqueológicas mucho más allá de El Tajín.

El silencio es una parte necesaria e innegable del hacer la historia; no se puede alcanzar una historia perfecta que encapsule el total (Trouillot 2017). Tampoco ha sido esta la finalidad de este estudio. Es más bien entender algo sobre cómo llegó a estar silenciado Modesto González, cómo se puede recuperar algo de su papel en la zona arqueológica El Tajín y cómo este proceso se podría llevar a cabo en otros sitios. Sin embargo, hay otras formas en que se puede desarrollar más este tipo de investigación.
Por ejemplo, retomando la perspectiva de Moro Abadía, podemos considerar "cuestiones importantes como la relación entre el presente y el pasado, la definición de entidades como arqueología y sociedad y el lugar de la arqueología en el conjunto de la sociedad" (2012: 185). Para llevar a cabo una investigación en estos términos, se podría seguir el rumbo de la teoría actor-red de Latour (2008). En una investigación así, la vida y obra de Modesto González es más bien el efecto de las interacciones entre una serie de actores humanos y no-humanos. Habrá que considerar, entonces, los papeles de personajes como Agustín García Vega, José García Payón, María Antonia Méndez y María Loreto al igual que los machetes, las coas, la sillita y el libro de registro que ocupó González para hacer su trabajo.

Como primer paso, la recuperación de una narrativa sobre la historia de la zona arqueológica de El Tajín a partir de un trabajador, Modesto González González, demuestra que las fuentes y la posibilidad de utilizarlas para escribir otras historias es posible, y es más necesario que nunca. Como apunta Trouillot, "Así, incluso en relación con el pasado, nuestra autenticidad reside en las luchas de nuestro presente. Sólo en ese presente podemos ser verdaderos o falsos respecto al pasado que elegimos admitir" (2017: 131). En este caso, defiendo que el pasado que resulta admisible incluye también a los trabajadores de la arqueología.

\section{Notas}

1. ITKEA, MSS 0122, Serie 2, c. 1, sin exp., "Oral historical, 21/5/1948," p. 4.

2. AHI-INAH, Colección CNRH, Serie Personal, caja 25, exp. 772, f. 3.

3. ITKEA, MSS 0122, Serie 2, c. 1, sin exp., "Oral historical, 21/5/1948," p. 4.

4. ITKEA, MSS 0122, Serie 2, c. 1, sin exp., "Oral historical, 21/5/1948," p. 5.

5. ITKEA, MSS 0122, Serie 2, c. 16, exp. 330202187, s/f.

6. AHI-INAH, Colección CNRH, Serie Personal, c. 25, exp. 772, f. 2.

7. AHI-INAH, Colección CNRH, Serie Personal, c. 25, exp. 772, f. 12; 13; 39.

8. AHI-INAH, Colección CNRH, Serie Personal, c. 84, exp. 2524, f. 295.

9. ITKEA, MSS 0122, Serie 2, c. 42, exp. 331718, s/f.

10. AHI-INAH, Colección CNRH, Serie Personal, c. 25, exp. 772, f. 11; 6.

11. ITKEA, MSS 0122, Serie 2, c. 16, exp. 34016, f. 64.

12. P. ej. AHI-INAH, Colección CNRH, Serie Personal, c. 42, exp. 1158, f. 13.

13. AHI-INAH, Colección CNRH, Serie Personal, c. 20, exp. 618, f. 29.

14. AHI-INAH, Colección CNRH, Serie Personal, c. 20, exp. 618, f. 30.

15. AGEV, Fondo Archivos Particulares, Sección José García Payón, c. 29, exp. 421, s/f. Carta de José García Payón a Jorge Enciso, 9/17/1947.

16. ADDMP, exp. El Tajín, ref. B/311/32(z61-2)/1, leg. 1, s/f. Ramón Castañeda a José Reygadas Vértiz, 24/10/1929. 
17. NAA, Isabel Kelly correspondence, c. 7, s/f. Isabel Kelly a George Foster, 27/1/1947.

18. NAA, Isabel Kelly correspondence, c. 7, s/f. Isabel Kelly a George Foster, 8/3/1947.

19. ITKEA, MSS 0122, Serie 2, c. 1.

20. ITKEA, MSS 0122, Serie 2, c. 1, sin exp., "Mythology, 7/5/1947."

21. ITKEA, MSS 0122, Serie 2, c. 42, exp. 330518, f. 17-18.

22. Con este termino se refiere al uso de camisa y calzón de manta blanca (véase Figura 2), lo cual se considera una señal importante de la filiación cultural totonaco vinculado con "lo tradicional." Para la indumentaria totonaca, véase el estudio de Masferrer y Vásquez (2013).

\section{Bibliografía}

Anderson, J. H. (2015). Three Generations of Cooperation: Voices from Tula, Hidalgo. Archeological Papers of the American Anthropological Association, 25, 90-99. http://doi.org/10.1111/apaa.12051

Ávila Hernández, R. J. (2007): La aportación de José García Payón a la arqueología

- Veracruzana. Monografía de licenciatura sin publicar, Universidad Veracruzana, Xalapa.

Berggren, A.; Hodder, I. (2003): Social Practice, Method, y Some Problems of Field Archaeology. American Antiquity 68(2): 421-434. https://doi.org/10.2307/3557102

Bernal, I. (1980): A History of Mexican Archaeology: the Vanished Civilizations of Middle America. Ruth Malet, trad. Thames y Hudson, New York.

Breglia, L. (2006). Monumental Ambivalence: The Politics of Heritage. University of Texas Press, Austin.

- (2005): Keeping World Heritage in the Family: a Genealogy of Maya Labour at Chichén Itzá. International Journal of Heritage Studies 11(5): 385-398. https://doi.org/10.1080/13527250500337421

Brizuela Abasalón, Á. (2009): José García Payón, pionero de la arqueología en Veracruz.

- Excavando en silencio: Los arqueólogos de ayer (L. Budar, S. Ladrón de Guevara, R. Lunagómez Reyes, eds). Universidad Veracruzana, Xalapa: 69-78.

Brueggemann, J. K. (1991): ¡Otra vez la cuestión totonaca! Antropología. Boletín oficial del INAH 34: 84-85.

- (ed.) (1992): Tajín. Gobierno del Estado de Veracruz, México, D.F.

- (1993): El problema cronológico del Tajín. Arqueología (9-10): 61-72.

Bueno, C. (2016):The Pursuit of Ruins: Archaeology, History, y the Making of Modern México. University of New México Press, Albuquerque.

Carruthers, W., \& Van Damme, S. (2017). Disassembling archeology, reassembling the modern world. History of Science, 55(3), 255-272. http://doi.org/10.1177/0073275317719849

Castillo Peña, P. (Ed.) (2011): Culturas del Golfo: Salvamento arqueológico y nuevas téchnicas. INAH/ PEMEX, México, D.F.

Daneels, A. (2006): José García Payón y Alfonso Medellín Zenil, pioneros de la arqueología del centro de Veracruz. Anales de antropología 40(1-2): 9-40. http://dx.doi.org/10.22201/iia.24486221e.2006.2.666

Du Solier, W. (1945): La cerámica arqueológica de El Tajín. Anales del Museo Nacional de Arqueología, Historia y Etnografía 5(3): 1-76.

Galindo y Villa, J. (1912): Las ruinas de Cempoala y del Templo del Tajín (estado de Veracruz)

- Exploradas por el Director del Museo Nacional de Arqueología, Historia y Etnología, in misión en Europa, Don Francisco del Paso y Troncoso. Museo Nacional de Arqueología, Historia y Etnología, México, D.F.

García Moll, R. (1982): Indice del Archivo Técnico de la Dirección de Monumentos Prehispánicos del INAH. INAH, México D.F.

García Payón, J. (1971): Archaeology of Central Veracruz. Handbook of Middle American Indians (R. Wauchope, ed), University of Texas Press, Austin: 502-542.

—; Ruiz Gordillo, J. O. (1993): José García Payón en Tajín. Arqueología Mexicana 1(5): 55-56.

García Vega, A. (1939): Exploraciones en El Tajín: Temporadas 1934 a 1938. Vigesimoseptimo Congreso Internacional de Americanistas: Actas de la primera sesión, celebrada en la Ciudad de México en 1939 (INAH, ed), INAH/Secretaria de Educación Pública, México, D.F.: 78-87.

Gándara, M. (1992): La Arqueología Oficial Mexicana: Causas y efectos. INAH, México, D.F.

Givens, D. R. (1992). The Role of Biography in Writing the History of Archaeology. 
— Rediscovering Our Past: Essays on the History of American Archaeology (J. E. Reyman, ed). Avebury, Aldershot: 51-65.

Gnecco, C.; Hernández, C. (2008): History and Its Discontents: Stone Statues, Native Histories, and Archaeologists. Current Anthropology 49(3): 439-466. https://doi.org/10.1086/588497

Hodder, I. (1989): Writing Archaeology: Site Reports in Context. Antiquity 63(239): 268-274. https://doi. org/10.1017/S0003598X00075980

Holley-Kline, S. (2015). Contextualizing Archaeology's "Locals": A Scalar Approach from El Tajín, Mexico. Archaeologies, 11(1), 70-92. http://doi.org/10.1007/s11759-015-9268-9

von Humboldt, A. (1811): Political Essay on the Kingdom of New Spain. J Black, trad. Longman, Hurst, Rees, Orme y Brown, London.

Kelly, I.; Palerm; A. (1952): The Tajín Totonac: Part I. History, Subsistence, and Technology. United States Government Printing Office, Washington, D.C.

Koontz, R. (2009): Lightning Gods and Feathered Serpents: The Public Sculpture of El Tajín. University of Texas Press, Austin

Kourí, E. (2013). Un pueblo dividido: comercio, propiedad y comunidad en Papantla, México. FCE/El Colegio de México, México, D.F.

Ladrón de Guevara, S. (2010): El Tajín: La urbe que representa al orbe. FCE, México, D.F.

Latour, B. (1987). Science in Action: How to Follow Scientists and Engineers through Society. Cambridge: Harvard University Press.

- (2008): Reensamblar lo social: Una introducción a la teoría del actor-red. Gabriel Zadunaisky, trad. Ediciones Manantial, Buenos Aires.

Leighton, M. (2016): Indigenous Archaeological Field Technicians at Tiwanaku, Bolivia: A Hybrid Form of Scientific Labor. American Anthropologist 118(4): 742-754. https://doi.org/10.1111/aman.12682

Lorenzo, J. L. (1981): Archaeology South of the Rio Grande. World Archaeology 13(2): 190-208. https:// doi.org/10.1080/00438243.1981.9979825

Lomnitz, C. (2001): Deep Mexico, Silent Mexico: An Anthropology of Nationalism. University of Minnesota Press, Minneapolis.

López Luján, L. (2008): El Tajín en el siglo XVIII: Dos exploraciones pioneras en Veracruz. Arqueología Mexicana 15(89): 74-81.

Martínez Acuña, O. (2010): Catálogo selectivo de la documentación de personal del Archivo Histórico Institucional del INAH. INAH, México, D.F.

Matos Moctezuma, E. (1998): Las Piedras Negadas: De la Coatlicue al Templo Mayor. CONACULTA, México, D.F.

Márquez, Pedro J. (1972): Sobre lo bello en general y dos monumentos de arquitectura mexicana: Tajín y Xochicalco (J. Fernández, ed.), UNAM-IIE, México, D.F.

Masferrer Kan, E.; Vásquez Valdés, V. (2013). Los totonacos a través de la mirada de Isabel Kelly. Dimensión Antropológica, 57: 161-177.

Mickel, A. (2019). Essential Excavation Experts: Alienation and Agency in the History of Archaeological Labor. Archaeologies, 15. http://doi.org/10.1007/s11759-019-09356-9

Moro Abadía, O. (2010): Beyond Externalism. Exploring New Directions in the History of Archaeology. Archaeological Dialogues 17(02): 215-236. https://doi.org/10.1017/S1380203810000280

- (2012): La nueva historia de la arqueología: Un balance crítico. Complutum 23(2): 177-190.

Murdock, G. P.; Clellan, F. S.; Hudson, A. E. (1945): Outline of Cultural Materials. Yale University Press, New Haven.

Nahmad Molinari, D. (1998): El Tajín: Una visión propia. Ciencias (49): 4-9.

Navarette, F. (2009). Ruinas y Estado: arqueología de una symbiosis mexicana. Pueblos indígenas y arqueología en América Latina (C. Gnecco; P. Ayala Rocabado, eds.). Fundación de Investigaciones Arqueológicas Nacionales, Banco de la República/CESO, Facultad de Ciencias Sociales, Universidad de los Andes, Bogotá: 65-82).

Nicholas, G.; Hollowell, J. (2007). Ethical Challenges to a Postcolonial Archaeology: The Legacy of Scientific Colonialism. Archaeology and Capitalism: From Ethics to Politics (Y. Hamilakis; P. Duke, eds.) Left Coast Press, Walnut Creek: 59-82

Olivé Negrete, J. C. (ed.) (1995): INAH, una historia. INAH, México, D.F.

Pascual Soto, A. (2009): El Tajín: Arte y poder. UNAM/INAH, México, D.F.

Pérez Lizuar, M. (2014). De Franz Boas a Ángel Palerm. Destacos (45): 13-26. 
Piña Chan, R.; Castillo Peña, P. (1999): Tajín: La ciudad del dios huracán. FCE, México, D.F.

Podgorny, I. (2015). Towards a Bureaucratic History of Archaeology. A Preliminary Essay. Historiographical Approaches to Past Archaeological Research (G. Eberhardt; F. Link, eds.). Edition Topoi, Berlin: 47-67.

Poniatowska, E. (1994): Luz y luna, las lunitas. Ediciones Era, México, D.F.

Riggs, C. (2017). Shouldering the past: Photography, archaeology, and collective effort at the tomb of Tutankhamun. History of Science, 55(3), 336-363. http://doi.org/10.1177/0073275316676282

Ruiz, A. (2016): Género, ciencia y politica. Voces, vidas y miradas de la arqueología mexicana. INAH, México, D.F.

Ruiz Gordillo, J. O. (1988): José García Payón. La Antropología en México: Panorama Histórica (C. García Mora; L. Odena Gümes, eds.), INAH, México D.F.: 133-138.

- (2002): Remembranzas: Análisis de la obra del arqueólogo José García Payón. INAH, México, D.F.

Rutsch, M. (2007): Entre el campo y el gabinete: Nacionales y extranjeros en la profesionalización de la antropología mexicana (1877-1920). INAH/UNAM-IIA, México D.F.

Salas Landa, Mónica. (2018): (In)Visible Ruins: The Politics of Monumental Reconstruction in Postrevolutionary Mexico. Hispanic American Historical Review 97 (1): 43-76. https://doi.org/10.1215/001821684294456

Secretaria de Desarrollo Regional. (2001): Programa de manejo: Entorno de El Tajín. Gobierno del Estado de Veracruz, Xalapa.

Simon, K. (1963): Mexico: Places and Pleasures. World Publishing Company, Cleveland.

Shapin, S. (1989). The Invisible Technician. American Scientist, 77(6), 554-563.

Shepherd, N. (2003): 'When the Hand That Holds the Trowel Is Black...' Disciplinary Practices of Self-Representation and the Issue of "Native" Labour in Archaeology. Journal of Social Archaeology 3(3): 334-352. https://doi.org/10.1177/14696053030033003

Trigger, B. G. (1984): Alternative Archaeologies: Nationalist, Colonialist, Imperialist. Man 19(3): 355370. https://www.doi.org/10.2307/2802176

Trouillot, M.-R. (2017): Silenciando el pasado: El poder y la producción de la historia. Miguel Ángel del Arco Blanco, trad. Editorial Comares, Granada.

Turner, S. (2010). Research Note: The Silenced Assistant. Reflections of Invisible Interpreters and Research Assistants. Asia Pacific Viewpoint 51(2): 206-219. https://doi.org/10.1111/j.1467-8373.2010.01425.x

Vásquez León, L. (2003). El Leviatán arqueológico: Antropología de una tradición cientifica en México. CIESAS, México, D.F.

Velázquez Hernández, E. (1995). Cuando los arrieros perdieron sus caminos: la conformación regional del Totonacapan. Zamora, Mich.: El Colegio de Michoacán.

Wilkerson, S. J. K. (1987). El Tajín: A Guide for Visitors. Universidad Veracruzana, Xalapa.

Williams García, R. (1989). La doctora Kelly en Tajín. Homenaje a Isabel Kelly (Y. González, ed.), INAH, México, D.F.: 29. 